\title{
Design, Analysis and Prototyping of Active Tab Rotor*
}

\author{
Noboru KobIKI, ${ }^{1) \dagger}$ Yasutada TAnabe, ${ }^{1)}$ Takashi Aoyama, ${ }^{1)}$ Do-Hyung KIm, ${ }^{2)}$ Hee Jung Kang, ${ }^{2)}$ \\ Seong-Yong WIE, ${ }^{2)}$ and Seung-Ho $\mathrm{KIM}^{2)}$ \\ ${ }^{1)}$ Aeronautical Technology Directorate, Japan Aerospace Exploration Agency, Mitaka, Tokyo 181-0015, Japan \\ ${ }^{2}$ Aeronautics Research and Development Head Office, Korea Aerospace Research Institute, Daejeon 34133, Korea
}

\begin{abstract}
The Japan Aerospace Exploration Agency (JAXA) and The Korea Aerospace Research Institute (KARI) jointly started activities related to the research and development of "Active Tab," a helicopter noise reduction technique. KARI constructed the analytical methodology consisting of the aerodynamic, structural dynamic and acoustic codes for defining the requirements to be used in evaluating the performance of Active Tab when installed in a Mach scaled assumed blade. Based on the requirements defined, JAXA carried out a conceptual design study, developed the Active Tab drive mechanism and evaluated its performance. The analytical results show Active Tab satisfying the requirements has sufficient noise reduction capability. Evaluation for the Active Tab drive mechanism demonstrated the dynamic performance and durability required practical use installed in helicopter blades.
\end{abstract}

Key Words: Active Tab, Helicopter, Noise Reduction Technique

\section{Introduction}

Among the noises generated by helicopters, the BladeVortex Interaction (BVI) noise causes significant damage and cannot be efficiently reduced using passive techniques such as airfoil/tip shape improvement. In order to resolve the BVI noise problem, many research organizations and helicopter manufacturers have been working to research/develop BVI noise reduction techniques for tens of years as one of the high priority technical tasks.

Several active techniques, such as HHC (Higher Harmonic Control), ${ }^{1-5)}$ IBC (Individual Blade Control), ${ }^{6-9)}$ Active Flap, ${ }^{10-15)}$ Active Twist ${ }^{16-18)}$ and others, have been proposed, researched and developed for helicopter noise/vibration reduction so far. Some of them were flight-tested and others are in the phase close to flight test evaluation.

The Japan Aerospace Exploration Agency (JAXA) and Kawada Industries Inc. have been working to research and develop a new active technique for helicopter noise reduction that is compatible with ICAO-defined flight patterns; namely, approach, fly over and take-off. ${ }^{19)}$

The schematic view of Active Tab, a newly developed mechanism, is shown in Fig. 1. Active Tab is installed in the aft portion of the airfoil and driven back and forth dynamically to reduce BVI noise and the vibration through the blade circulation control caused by the variable blade area effect with the aim of the low power consumption.

Active Tab can also be operated statically, such as Active Tab is deployed with some displacement and fixed. Operation using fixed Active Tabs increases blade lift throughout

(C) 2019 The Japan Society for Aeronautical and Space Sciences

*Presented at the 41st European Rotorcraft Forum, September 1-4, 2015, Munich, Germany.

Received 6 June 2017; final revision received 15 March 2018; accepted for publication 3 September 2018.

†Corresponding author, kobiki.noboru@jaxa.jp the full revolution of the blade, enabling the rotor speed to be reduced by using the lift increment. This has effects both climb and fly-over noise reduction..$^{20,21)}$

Compared to Active Tab, the previously mentioned existing active techniques have the following drawbacks.

The HHC actuator moves the whole blade on a non-rotating frame; a technique that has two drawbacks. One is that much power is required to drive the non-rotating and rotating swashplates and the inner portion of the blade as well, which are aeroacoustically idle parts. The other is that the higher harmonic pitch frequency generated on the rotating blade is limited to $b \Omega$ and $(b \pm 1) \Omega$, where $b$ and $\Omega$ stand for the number of blades and rotor speed, respectively.

IBC drives the whole blade, but does so using an actuator that is installed on the rotating frame. This technique largely mitigates the first drawback of $\mathrm{HHC}$ and completely eliminates the latter, but doing so at the cost of requiring a complicated hydraulics system that transmits high-pressure actuation fluid with large flow rate from the non-rotating frame to the rotating frame.

Active Flap drives a small flap installed at the trailing edge of a blade tip portion. This technique is power-effective compared with HHC and IBC, because only the aeroacoustically useful blade tip part is driven. The flap is controlled using an on-board smart actuator. This technique has become practi-

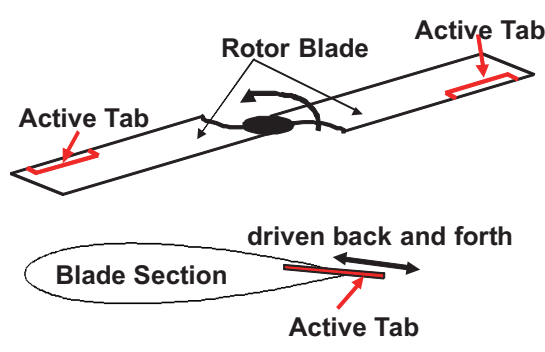

Fig. 1. Active Tab concept. 
cal following a recent breakthrough in smart actuator technology, although there is still an issue with the flap drive system regarding a mechanical component: there is a problem with achieving sufficient stable large flap amplitude under the condition of high centrifugal force.

Active Twist twists a blade directly using an actuator sheet installed along the blade span underneath the skin without any mechanical component between the actuator and blade, which makes this technique the best power-effective among the four mentioned. The effort to generate sufficient large blade tip amplitude to reduce rotor noise is going on.

In terms of noise reduction, these existing active techniques are efficient for the BVI noise generated when approaching the landing area, and represents a large part of the issue related to public acceptance of helicopter use. However, compared to effectiveness for approach flight patterns, these techniques are either not very useful or not very efficient in terms of reducing noise during climb and fly-over flight patterns..$^{20,21)}$

JAXA and the Korea Aerospace Research Institute (KARI) jointly started activities related to the research and development of active technologies for helicopter noise reduction in 2009 to provide technical solutions for the above mentioned problem. Both parties agreed on Active Tab as the target active technique for this joint research program.

The basic research for Active Tab had been carried out by JAXA and Kawada Industries Inc. using a 1-bladed rotor system on a low tip speed $(62.8 \mathrm{~m} / \mathrm{sec})$ condition. ${ }^{20-22)}$ However, the rotor tip speed is generally $200-220 \mathrm{~m} / \mathrm{sec}$ to satisfy the Mach scaled condition simulating the compressibility effects. It is demonstrated by this phase of the study in a rotor configuration that Active Tab has the ability to efficiently control rotor noise, and is thus a promising technique for reducing rotor noise.

As the next step, the JAXA/KARI joint research program is prepared an experiment to demonstrate Active Tab capability using a 2-bladed rotor system under Mach scaled conditions, which simulates a more realistic environment for helicopter rotors than the 1-bladed rotor system did.

In the framework of this joint research program, KARI had the responsibility to provide an existing rotor system with newly designed blades in which Active Tab could be installed. On the other hand, JAXA developed the drive mechanism for Active Tab. Both of the parties developed analytical methods to evaluate the noise reduction capability of Active Tab rotor.

This paper describes the methodology used for Active Tab rotor development, consisting of the design, analysis and prototyping of Active Tab hardware.

\section{Active Tab Rotor Modeling}

In order to analyze the effect of Active Tab on the aeroacoustic characteristics, CAMRAD II model was prepared and the airloads were predicted, and then BVI noise characteristics were calculated.
Table 1. Rotor properties.

\begin{tabular}{ll}
\hline \multicolumn{1}{c}{ Properties } & \multicolumn{1}{c}{ Values } \\
\hline No. of blades & 2 \\
Hub type & teetering \\
Rotating direction & counter clockwise \\
Rotating speed & $1,300 \mathrm{rpm}$ \\
Radius & $1.5 \mathrm{~m}$ \\
Chord length & $0.12 \mathrm{~m}$ \\
Airfoil & NACA0015 \\
Twist & $-8 \mathrm{deg}$ linear \\
Root cut-out & $0.17 R$ \\
\hline
\end{tabular}

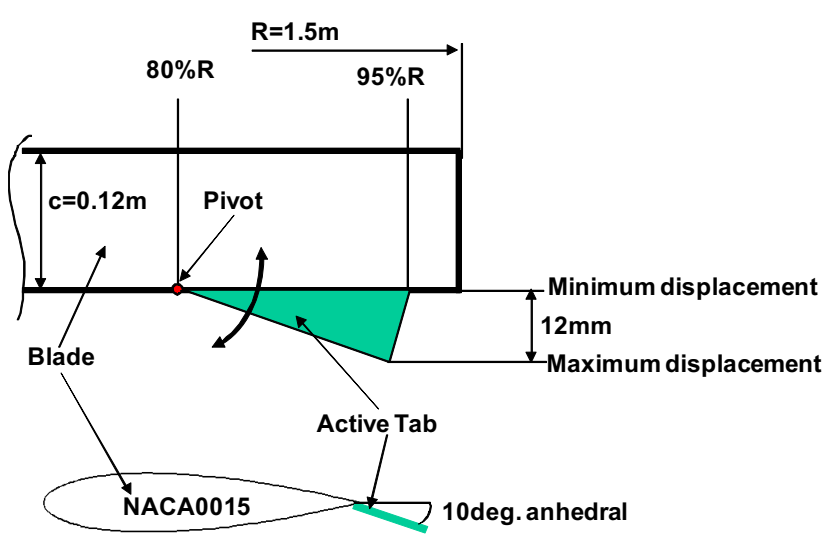

Fig. 2. Active Tab installation. ${ }^{23)}$

\subsection{Rotor system}

A 2-bladed model rotor system with a $1.5 \mathrm{~m}$ radius and a teetering hub was designed for implementing Active Tab considering the size of the Active Tab drive mechanism and the capability of the rotor test stand. The general properties of the model rotor system are given in Table 1 .

\subsection{Active Tab}

Based on the achievement of wind tunnel tests using a 1bladed rotor system, ${ }^{20,21)}$ the features of Active Tab for the Mach scaled blade are defined and its schematic drawing is shown in Fig. 2.

The tab is fan-shaped so that the extended area generated at the time of tab operation is made larger in the outer portion of the blade where the dynamic pressure is higher than that in the inner portion. A $10 \mathrm{deg}$ anhedral angle is given to the tab so that the tab effect on the blade lift increment is augmented. The Active Tab is pivoted at its apex to a position that is $80 \% R$ location of the blade. NACA0015 is selected as the airfoil of the blade in order to provide sufficient thickness to store the drive mechanism of the Active Tab without creating a significant disadvantage to the maximum lift of the blade.

To enable a simple understanding of the Active Tab effect, it is modeled as a rectangular instead of being fan-shaped, as shown in Fig. 3. Additional airfoil tables with different tab chord lengths were generated for the sections from $0.8 R$ to $0.95 R$; which was implemented in the CAMRAD II model.

The Active Tab drive mechanism is composed of a piezoelectric actuator and mechanical parts that amplify the ampli- 


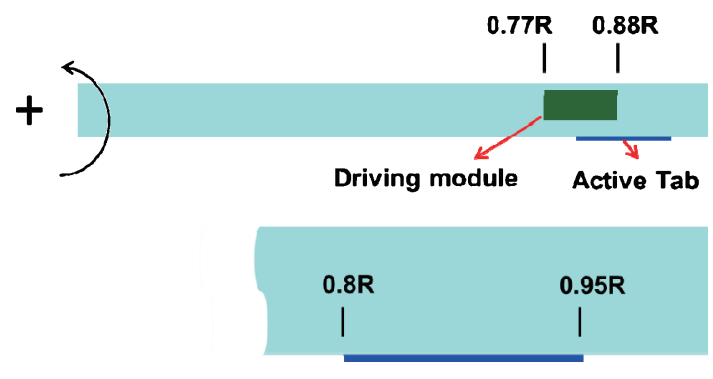

Fig. 3. Tab location.

Table 2. Inertial properties of driving module.

\begin{tabular}{ll}
\hline \multicolumn{1}{c}{ Properties } & \multicolumn{1}{c}{ Values } \\
\hline Mass & $360 \mathrm{~g}$ \\
Moment of inertia & $1.71 \times 10^{-4} \mathrm{kgm}^{2}$ \\
Center of gravity & $0.84 R / 0.3749 \mathrm{c}$ \\
\hline
\end{tabular}

tude of the actuator displacement and transform the actuator output into Active Tab motion. The driving mechanism is installed inside the blade, and the inertial properties are modeled as a lumped mass in the structural part of the CAMRAD II model. The inertial properties of the driving mechanism are shown in Table 2.

\subsection{Construction of aerodynamic tables for airfoil with} tab

Analyzing an Active Tab rotor using CAMRAD II requires aerodynamic tables for airfoils with a tab, and the tab chord length must be considered in order to simulate the Active Tab rotor.

Aerodynamic tables for flow conditions of the airfoil with the angle of attack ranging from $-16 \mathrm{deg}$ to $+16 \mathrm{deg}$ and Mach numbers ranging from 0.1 to 1.0 were constructed using Fluent of ANSYS software. The numerical calculations for lift, drag and moment coefficients of the airfoil with a tab were performed for the range of tab chord lengths from 0 to $12 \mathrm{~mm}$ at $2 \mathrm{~mm}$ intervals.

The density-based Reynolds Average Navier-Stokes (RANS) flow solver with Roe's flux-difference splitting and least-square reconstruction for the 2nd order scheme in Fluent was used. The effect of turbulence was estimated using the Spalart-Allmaras one-equation model.

The pressure far-field boundary condition was placed at 30 times that of the airfoil chord length and the no-slip condition on the airfoil surface was applied. Figure 4(a) shows the computational mesh distribution around the airfoil and Fig. 4(b) shows that around the tab. Meshes around the airfoil surface and behind the trailing edge were refined to resolve the viscous effect and wake. A 25-layer prism mesh was also applied for the airfoil surface.

For the high angle of attack range, aerodynamic tables were constructed using the analytic model described by Leishman. ${ }^{24)}$

\subsection{Blades}

The model blade was designed following the procedure shown in Fig. 5.

In order to produce sufficient elastic torsion deformation

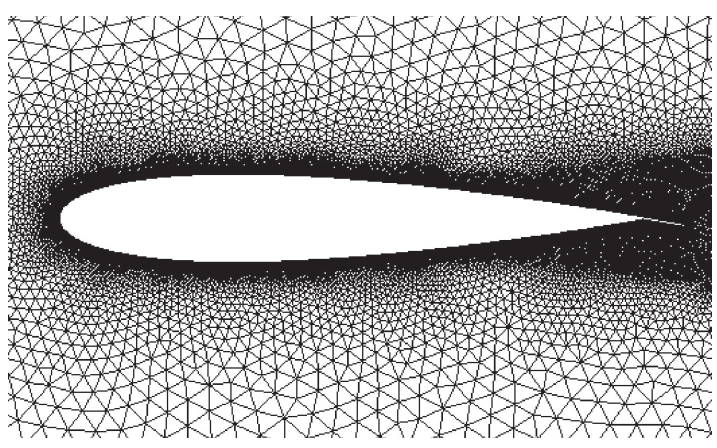

(a) Around airfoil

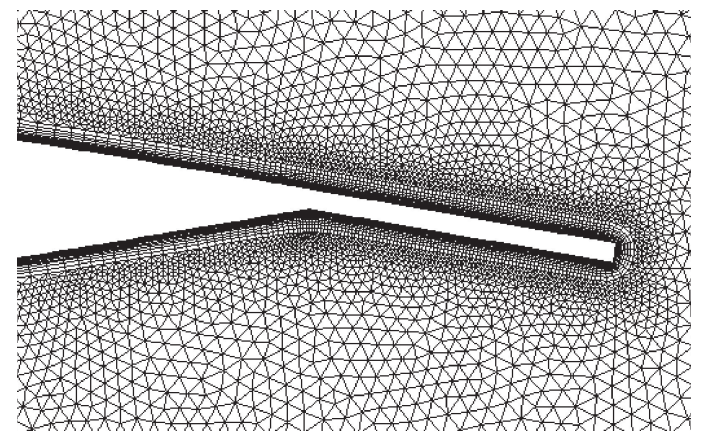

(b) Around tab

Fig. 4. Computational mesh distribution around the airfoil and tab.

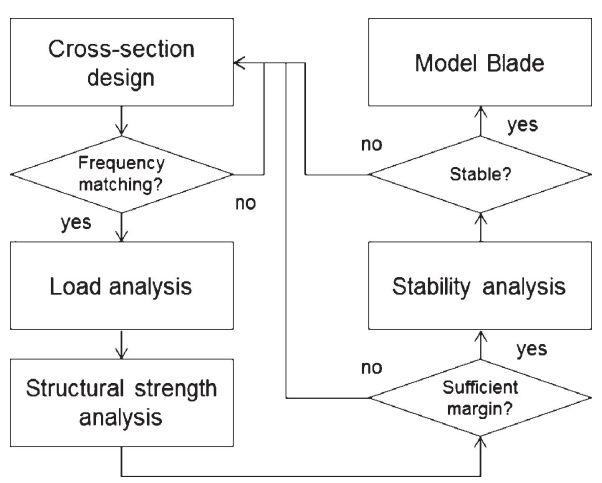

Fig. 5. Blade design procedure.

produced through Active Tab movement, the target torsion frequency was selected to be close to $4 / \mathrm{rev}$.

\subsubsection{Cross section design}

Three sections of the blade with D-shape spar were designed and a transition region was generated using interpolation. A typical section for the main lifting area is shown in Fig. 6. The primary materials for blade structure are carbon fabric/epoxy prepreg and unidirectional (UD) carbon/epoxy prepreg, and tungsten rods are used for weight balance. Mainly, a [0/90] stacking angle is utilized for realizing a relatively low first torsion frequency. KARI's in-house program, Composite Rotor blade Design and Analysis Software (CORDAS) was used for designing and analyzing the blade cross sections.

\subsubsection{Dynamic analysis}

For checking the frequency placement of the blade, a fanplot analysis was performed. The first torsion frequency is 


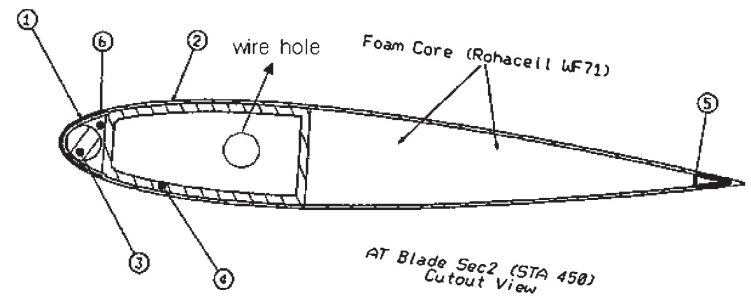

(1) nose skin : [0/90] carbon fabric 2-plies

(2) skin: [0/90] carbon fabric 3-plies

(3) balance weight: tungsten rod $6 \mathrm{~mm}$ diameter

(4) spar: [0/90] carbon fabric 8-plies

(5) TE stiffener: [0] UD carbon

(6) LE stiffener: [0] UD carbon

Fig. 6. Typical section view.

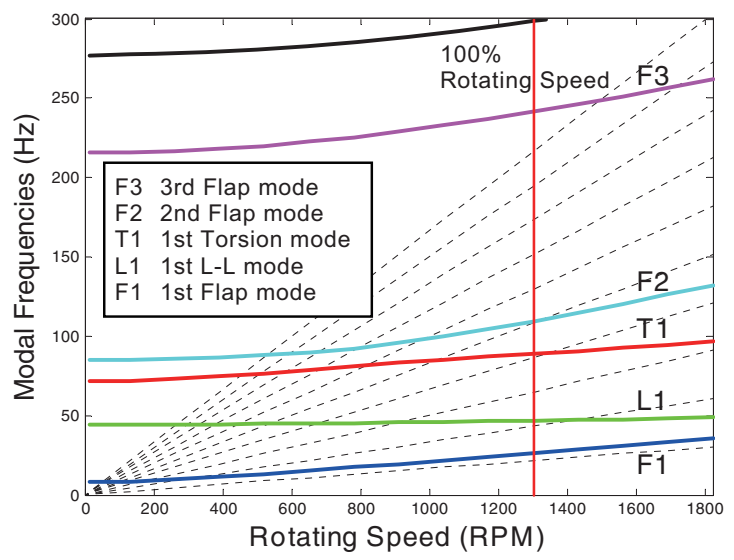

Fig. 7. Fan-plot of the designed blade.

close to $4 /$ rev as shown in Fig. 7.

Although the first lead-lag mode showed very low modal damping, the aeroelastic instability, which is represented by the negative damping ratio, was not observed on the hover conditions with collective pitch variations as shown in Fig. 8.

\subsubsection{Load analysis}

A blade load analysis was performed during hover, forward flight with an advance ratio of 0.25 , and descent flight with an advance ratio of 0.15 .

Figure 9 shows the blade spanwise load distribution during forward flight that produced the largest structural load among the three flight conditions. Discontinuous load distribution can be seen in the structural element including the Active Tab drive mechanism as a lumped mass and large bending moments are acting in the inboard region.

\subsubsection{Strength analysis}

The maximum strain at the skin was calculated using the combined load composed of axial force, flap and lag moments. The structural safety factor was then calculated based on the allowable material strain for the design. The ultimate load was applied as 1.5 times limit load, and $70 \%$ of the failure strain was used as the allowable strain for the design. ${ }^{25)}$

The minimum safety factors calculated for hovering, level flight $(\mu=0.25)$, and descent $(\mu=0.15)$ were $3.27,2.96$,

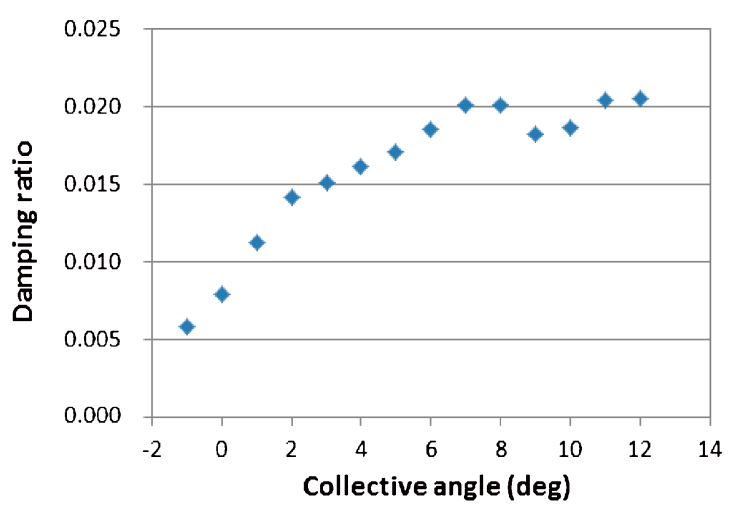

Fig. 8. First lag mode damping on hover.
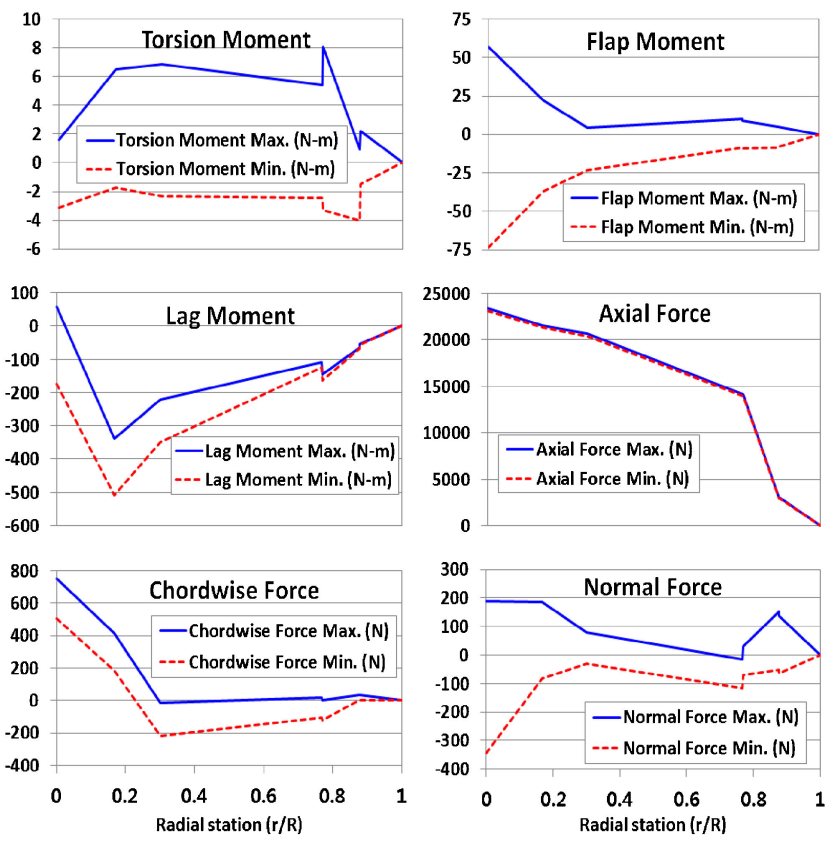

Fig. 9. Blade load distribution (forward flight).

and 3.21, respectively. Therefore, the blade itself has sufficient static structural strength.

\section{Evaluation of Aerodynamic and Acoustic Charac- teristics}

Airload prediction was performed using CAMRAD II, and then the noise level was evaluated using an in-house program. The multiple trailers, with the consolidation option, were used for the wake model, and the ONERA EDLIN model $^{26)}$ was used for the unsteady aerodynamic load calculation. The post-trim was applied to get 2 deg azimuthal step high resolution airload data.

\subsection{Rotor trim}

A three-variable propulsive trim was applied, with the three trim targets being thrust $(F z)$, propulsive force $(F x)$, and zero rolling moment $(M x=0)$, and the shaft was fixed at a specified angle. This is a time-saving approach compared to four-variable trim (trim targets $F z, F x, M x=M y=0$ ) used in wind tunnel testing. ${ }^{27)}$ Three control inputs $(\theta 0, \theta 1 \mathrm{C}$, 


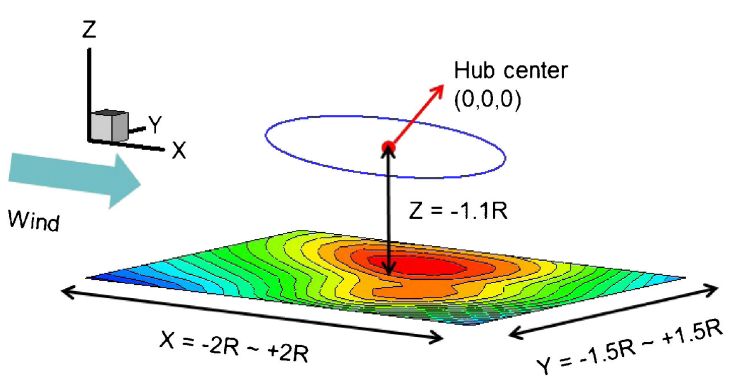

Fig. 10. Noise calculation map.

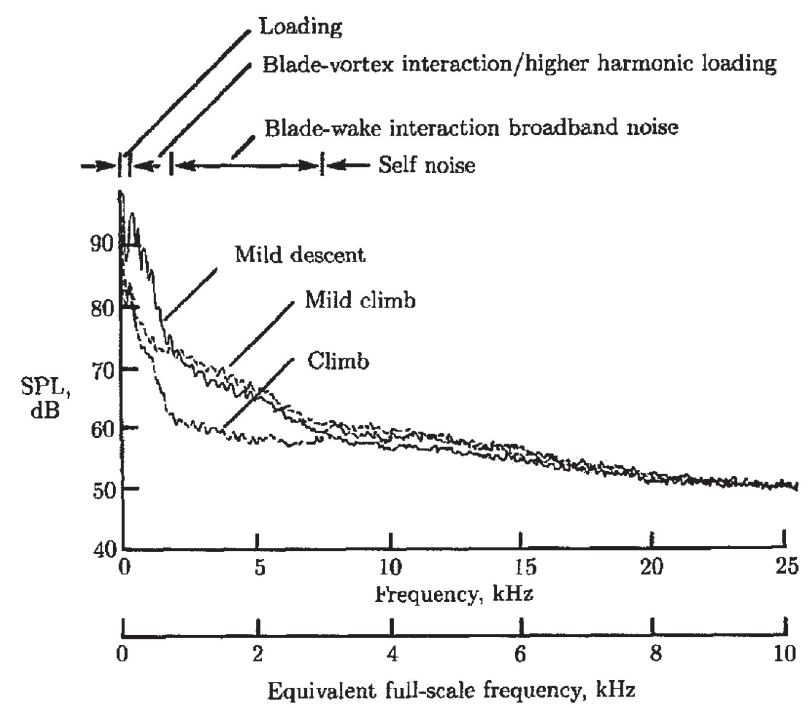

Fig. 11. Typical overhead noise spectra of 2/5-scale BO-105 model rotor. $^{29)}$

and $\theta 1 \mathrm{~S})$ are used to match three targets. Three-variable propulsive trim has an advantage of having matched propulsive force. However, large longitudinal flapping can be produced if the shaft tilt angle is not properly set up.

\subsection{Acoustic analysis methodology}

For rotor noise prediction, the Farassat formulation $1 \mathrm{~A},{ }^{28)}$ based on the Ffowcs-Williams Hawkings (FW-H) equation, is used. The Farassat formulation is implemented using monopole and dipole noise terms and each term represents thickness and loading noise, respectively. To consider the retarded time calculation, a source-time dominant algorithm and wind effect correction were applied to the acoustic analysis code. The input (airload and blade deformation information) for the acoustic analysis was calculated using CAMRAD II. Using the acoustic analysis code, the acoustic pressure signal and Sound Pressure Level (SPL) were calculated at observer positions.

Figure 10 shows the map for noise calculation. It is located $1.1 R$ below the hub center, having an area of $3 R$ by $4 R$. The positive direction of each axis is the downstream wind direction $(X)$, and the starboard $(Y)$ and lift $(Z)$ directions.

The BVI noise can be identified as the mid-frequency contents in noise spectra, as shown in Fig. 11. It is dominant under descent flight conditions, and a suitable frequency

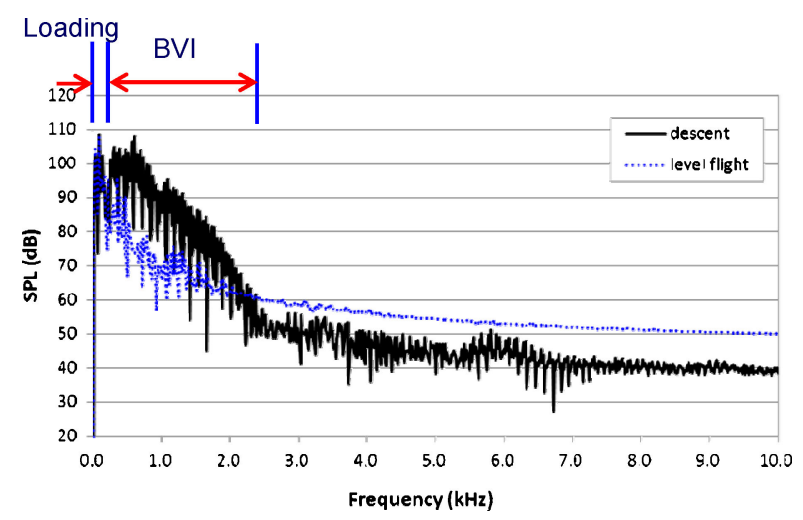

(a) Noise spectra (linear scale)

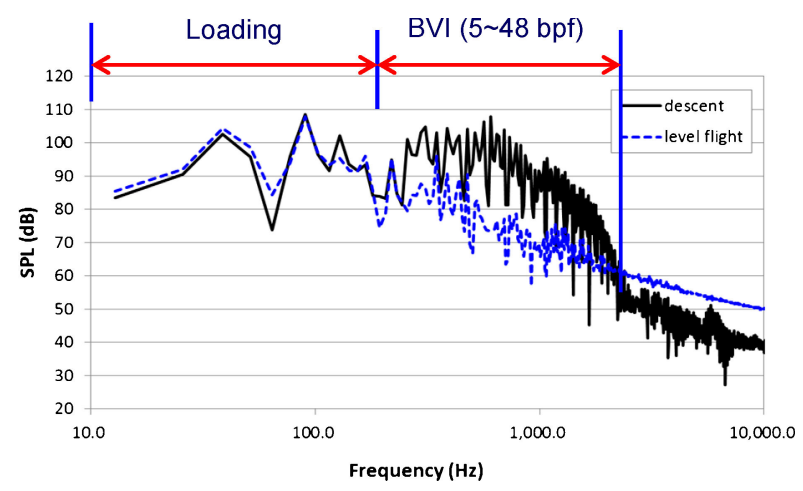

(b) Noise spectra (log scale)

Fig. 12. Comparison of noise spectra under descent and level flight conditions.

range can be distinguished by comparing noise spectra of the descent and other flight conditions.

The noise spectrum of the descent flight (advance ratio 0.15 , shaft tilt angle $7.1 \mathrm{deg}$ ) is compared with that of level flight at the same flight speed (advance ratio 0.15, shaft tilt angle $-1.9 \mathrm{deg}$ ) shown in Fig. 12.

SPLs at the same location $(X=-0.25 R, Y=0.75 R$, $Z=-1.1 R$ ) show that the levels of low-frequency loading noise are almost the same, but the strong noise contents can be found in the mid-frequency range under descent flight conditions. The frequency range of this area is a blade passing frequency (bpf) of 5-48, and SPL due to this frequency range is denoted as BVISPL (Blade Vortex Interaction Sound Pressure Level).

\subsection{Baseline flight conditions}

The conditions resulting in maximum BVI noise were selected as the baseline flight conditions in order to clearly bring out the effect of Active Tab on BVI noise reduction. The shaft angle sweep was performed during descent flight at the same wind speed $31 \mathrm{~m} / \mathrm{sec}$ (advance ratio 0.15). The airframe drag and rotor drag were considered for setting the shaft tilt angle. The equivalent flat plate area of the rotor test stand was used for the airframe drag $(F x=59 \mathrm{~N})$ calculation and the mean airfoil drag was used for rotor drag $(H=8 \mathrm{~N})$. The target thrust was selected to match the scaled 
Table 3. Shaft angle sweep conditions.

\begin{tabular}{cccc}
\hline \multirow{2}{*}{$\begin{array}{c}\text { Flight path angle } \\
(\mathrm{deg})\end{array}$} & $\begin{array}{c}\text { Shaft tilt angle } \\
(\mathrm{deg})\end{array}$ & \multicolumn{2}{c}{ Trim target } \\
\cline { 3 - 4 } & 3.1 & $4.38396 \mathrm{E}-04$ & $7.99306 \mathrm{E}-02$ \\
5 & 4.1 & $4.38396 \mathrm{E}-04$ & $7.98916 \mathrm{E}-02$ \\
6 & 5.1 & $4.38396 \mathrm{E}-04$ & $7.98526 \mathrm{E}-02$ \\
7 & 6.1 & $4.38396 \mathrm{E}-04$ & $7.98137 \mathrm{E}-02$ \\
8 & 7.1 & $4.38396 \mathrm{E}-04$ & $7.97749 \mathrm{E}-02$ \\
9 & 8.1 & $4.38396 \mathrm{E}-04$ & $7.97361 \mathrm{E}-02$ \\
\hline 10 & & & \\
\hline
\end{tabular}

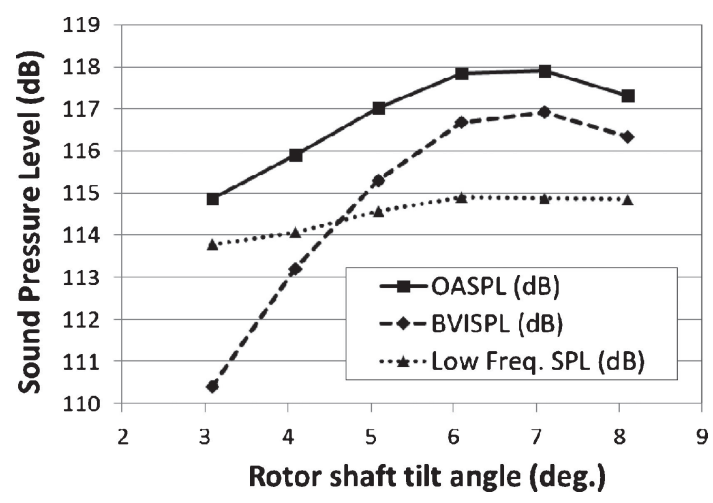

Fig. 13. SPL variations with respect to rotor shaft tilt angle.

weight of AH-1G with a scale factor of 4.47 , which is $W=1,473 \mathrm{~N}$. The computation was performed at various shaft angles listed in Table 3 with thrust, propulsive force, and zero rolling moment trim targets.

The maximum SPL of each case in Table 3 is compared in Fig. 13. The maximum OASPL (Overall SPL) and BVISPL were observed at the shaft tilt angle of $7.1 \mathrm{deg}$; which is selected as the baseline (BL) condition.

\section{Prototype Development for Active Tab Drive Mech- anism}

\subsection{Requirements}

Based on the experimental results ${ }^{20,21)}$ and analytical prediction, the requirements for Active Tab are set as follows. Active Tab:

Span length: $80-95 \% R$

Maximum displacement: $12 \mathrm{~mm}$

Frequency: $2 / \mathrm{rev}(43.3 \mathrm{~Hz})$ with $20 \mathrm{~N}$ simulated lift acted on tab

Instrumentation:

Active Tab displacement

Hinge moment

Output displacement of the double armed amplifier

Actuator displacement

Input voltage to actuator

The inertial properties of the driving mechanism described in Table 2 are requirements as well.

\subsection{Conceptual study}

A conceptual design study of Active Tab in order to be installed in a Mach scaled assumed blade was carried out. ${ }^{30)}$ Then, the prototype of the Active Tab drive mechanism

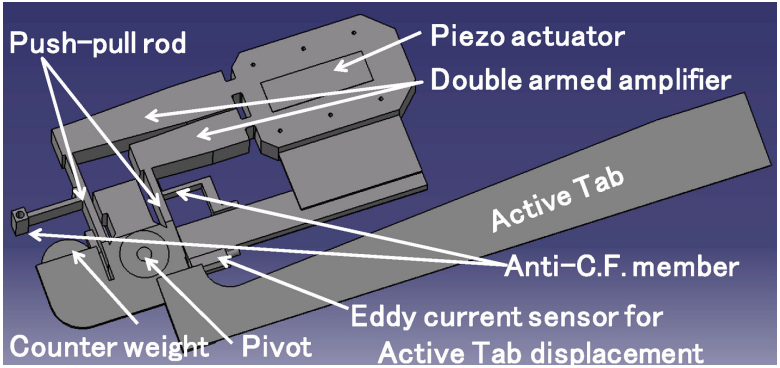

Fig. 14. Active Tab drive mechanism.

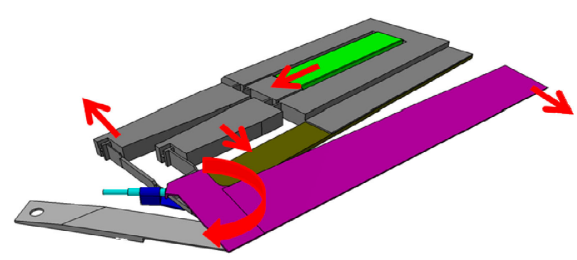

(a) Active Tab extension process

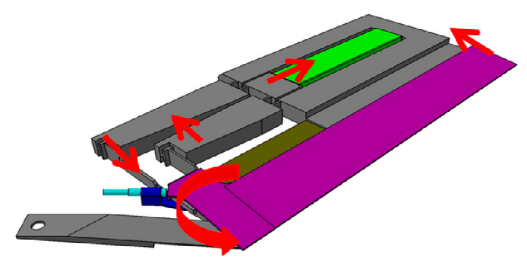

(b) Active Tab retrieving process

Fig. 15. Active Tab deployment sequence.

shown in Fig. 14 was developed based on the conceptual design study. ${ }^{23,31,32)}$

A single stacked piezo actuator stored in a casing generates linear reciprocal movement, which is magnified by the double armed amplifier and transformed into rotary displacement of the arms around the pivot. Then, Active Tab is driven via a pivot in a reciprocal rotational direction. A counter weight is connected on the opposite side of Active Tab across the pivot in order to cancel the centrifugal force acting about the pivot.

The Active Tab deployment sequence is shown in Fig. 15. The Active Tab extension process is depicted in Fig. 15(a). At first, the piezo actuator (green part) extends. This movement spreads each arm (gray parts) of the amplifier, which generates torque around the pivot in the direction of making Active Tab (purple part) rotationally spread around the pivot. The opposite happens in the retrieving process, which is initiated by the piezo actuator shrinking as depicted in Fig. 15(b).

\subsection{System design and development}

The Active Tab drive mechanism is developed as shown in Fig. 16. It is geometrically suitable for the blade assumed in this study and satisfies the requirements described in Section 4.1 .

All of the measurements except the input voltage to the actuator are measured by strain gauges in the Active Tab drive mechanism. The position of the strain gauge for each item measured is shown in Fig. 17. 


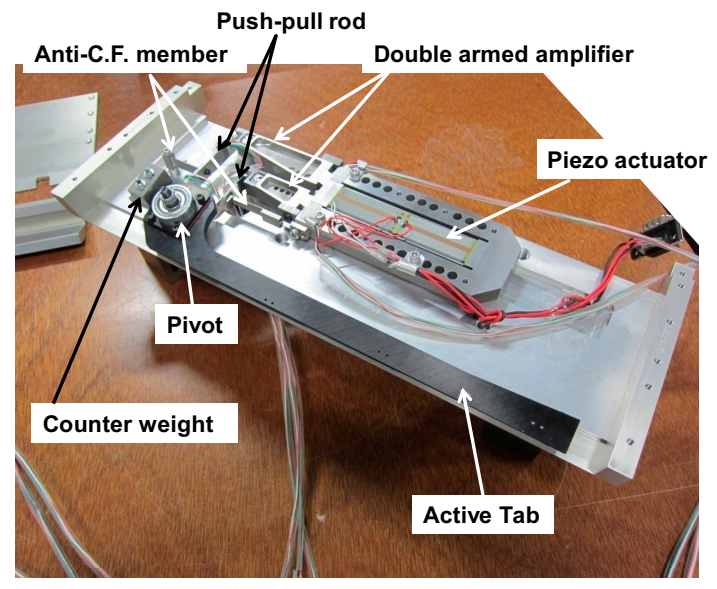

Fig. 16. Finalized Active Tab drive mechanism with simulated blade.

\section{Output displacement of the double armed amplifier and Actuator displacement}

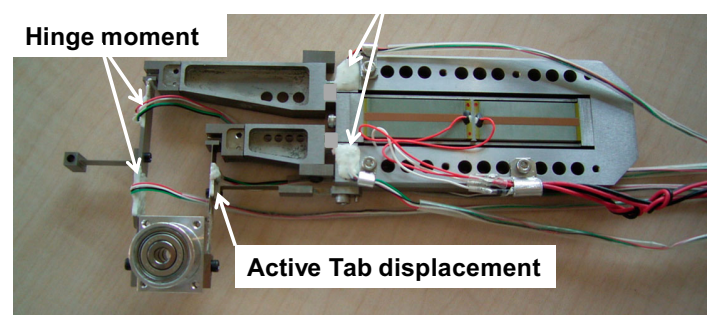

Fig. 17. Strain gauge position for instrumentation.

The unsteady Active Tab displacement is measured by the strain gauge on the shorter push-pull rod. The hinge moment is measured by the gauges on the longer push-pull rod, the output displacement of the double armed amplifier and the actuator displacement are done by gauges on the base portion of the double armed amplifier.

\section{Results and Discussion}

\subsection{BVI noise under baseline conditions}

The blade section normal force distribution is shown in Fig. 18. The azimuthal fluctuation of the normal force due to BVI is found in advancing and retreating sides. Figure 19 is the BVISPL noise map for baseline conditions. The maximum BVISPL can be found in the second quadrant and the direction of BVI noise propagation is about $110 \mathrm{deg}$.

\subsection{Active Tab effect on BVI noise}

The variations in the BVISPL were investigated by applying HHC (Higher Harmonic Control) actuation to Active Tab. Active Tab displacement is defined as follows:

$$
A=\frac{A_{n}}{2}+\frac{A_{n}}{2} \cos \left(n \varphi-\varphi_{n}\right), \quad(n=2,3)
$$

where, $A$ is the tab displacement extracted from the trailing edge of the blade, $A_{n}$ is the amplitude demand, $n$ is the order of harmonics, $\varphi$ is the azimuth angle, and $\varphi_{n}$ is the control phase angle. In this study, the characteristics of BVI noise were investigated using $n=2,3(2 / \mathrm{rev}$ and $3 / \mathrm{rev}) \mathrm{HHC}$ actuations with $A_{n}=3,6,9$ and $12 \mathrm{~mm}$, and $\varphi_{n}=0-330 \mathrm{deg}$

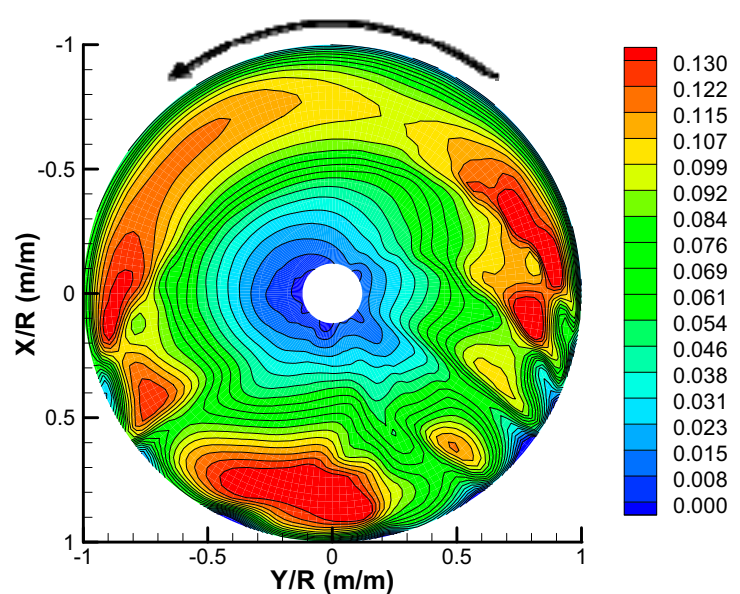

Fig. 18. Section normal force (M2Cn, BL).

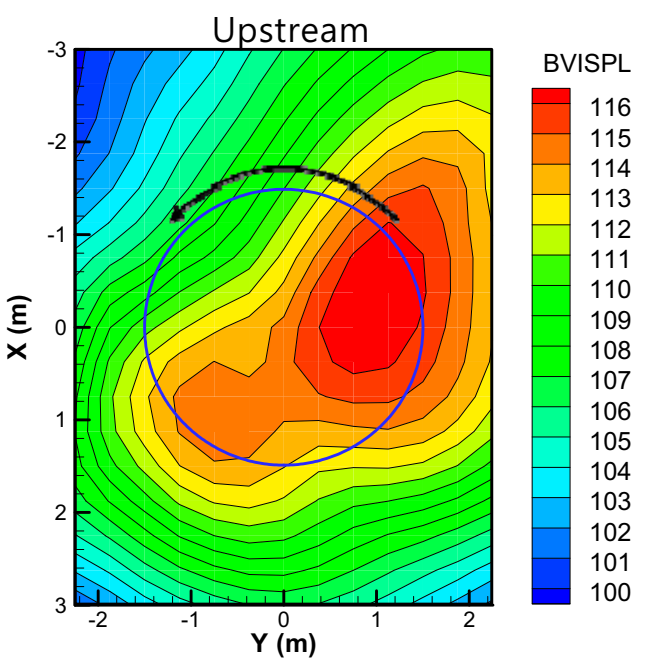

Fig. 19. Noise map (BVISPL, BL).

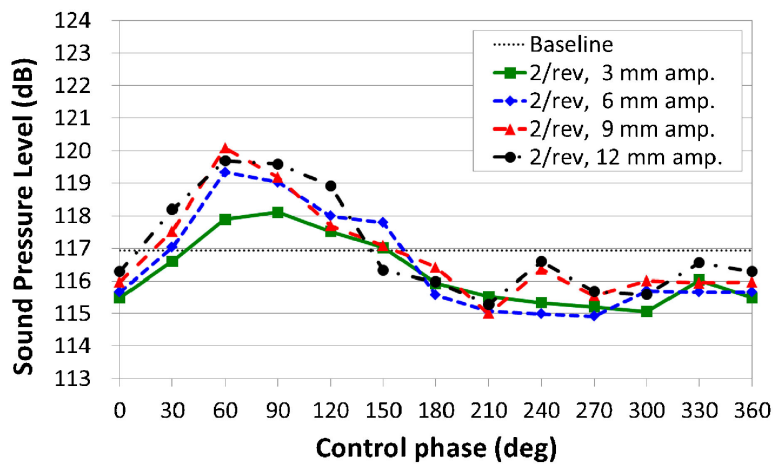

Fig. 20. Maximum BVISPL variations (2/rev actuation).

with 30 deg interval.

For $2 /$ rev actuation, BVISPL changes with respect to Active Tab amplitude and control phase angle are shown in Fig. 20. Maximum BVISPL is reduced with control phase angles 150-30 deg. BVISPL also changed according to the control amplitude, but the waveforms with different amplitudes are similar. The minimum noise condition was found at $A_{n}=6 \mathrm{~mm}$ amplitude and $\varphi_{n}=270 \mathrm{deg}$ control phase. The amount of BVISPL reduction was $2.0 \mathrm{~dB}$. 


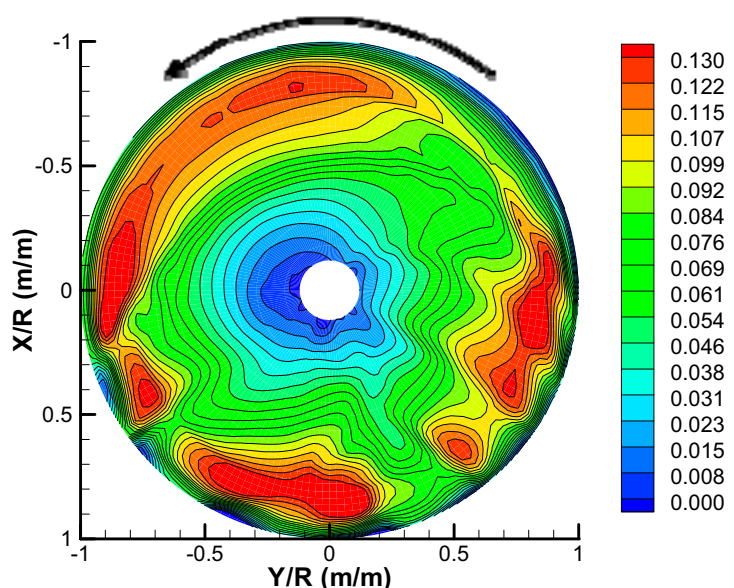

Fig. 21. Section normal force (M2Cn, MN-2P, $A_{n}=6 \mathrm{~mm}$, $\varphi_{n}=270 \mathrm{deg}$ )

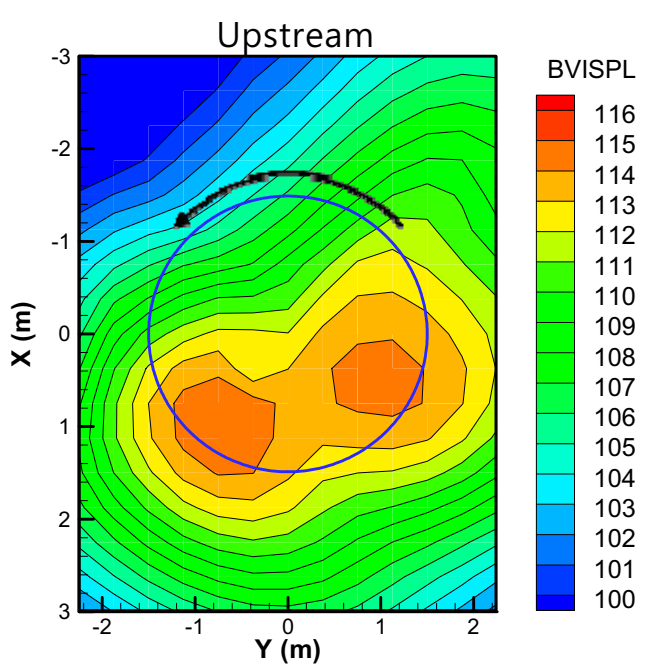

Fig. 22. Noise map (BVISPL, MN-2P, $A_{n}=6 \mathrm{~mm}, \varphi_{n}=270$ deg).

The blade section normal force distribution for the minimum noise condition with $2 /$ rev actuation is shown in Fig. 21 and the noise map is shown in Fig. 22. The normal force fluctuation was alleviated on the advancing side and the location of peak BVISPL is observed $60 \mathrm{deg}$ in the azimuthal direction.

For $3 /$ rev actuation, BVISPL changes are shown in Fig. 23. BVI noise reduction can be achieved with control phase angles of 270-120 deg. The minimum noise condition was found at $A_{n}=6 \mathrm{~mm}$ amplitude and $\varphi_{n}=30 \mathrm{deg}$ control phase. The amount of BVISPL reduction was $3.3 \mathrm{~dB}$.

The blade section normal force distribution for the minimum noise condition with $3 / \mathrm{rev}$ actuation is shown in Fig. 24 and the noise map is shown in Fig. 25. Normal force fluctuation is much smoother on the advancing side. The direction of peak BVISPL location was similar to the minimum noise condition with $2 / \mathrm{rev}$ actuation, but the maximum BVISPL was reduced $3.3 \mathrm{~dB}$, which is a gain of $1.3 \mathrm{~dB}$ higher than $2 /$ rev actuation. Therefore, $3 /$ rev actuation was more effective within calculation ranges used for this study.

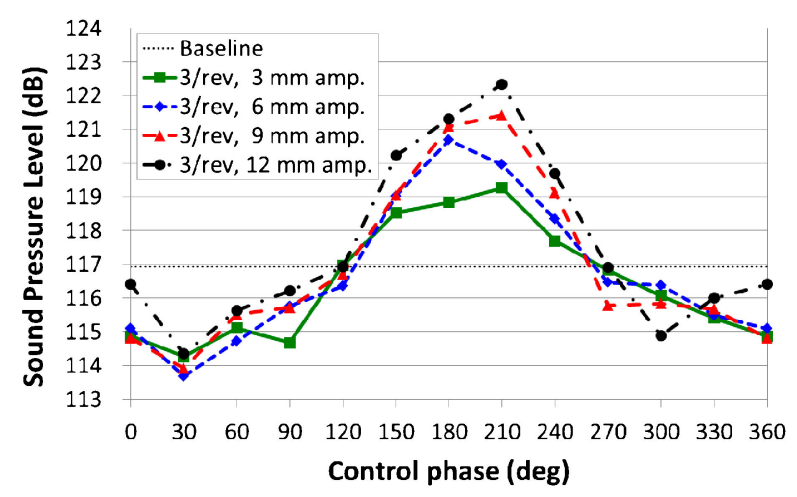

Fig. 23. Maximum BVISPL variations (3/rev actuation).

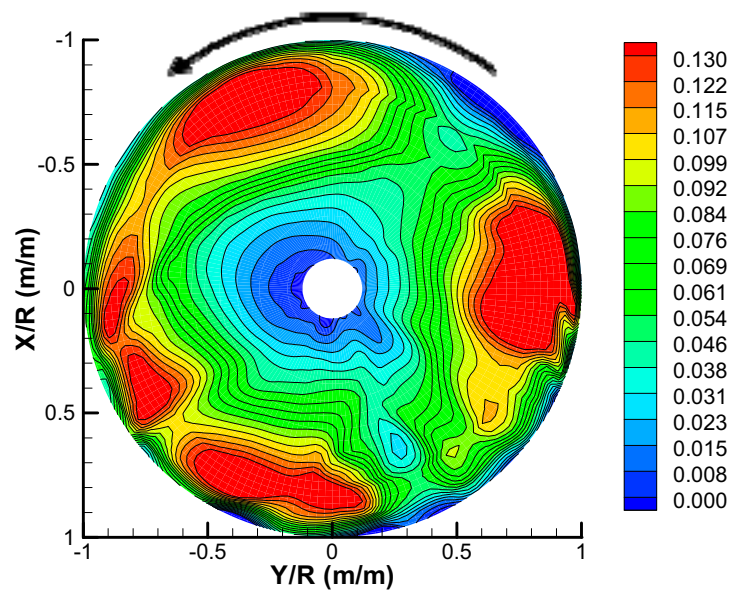

Fig. 24. Section normal force (M2Cn, MN-3P, $A_{n}=6 \mathrm{~mm}$, $\left.\varphi_{n}=30 \mathrm{deg}\right)$.

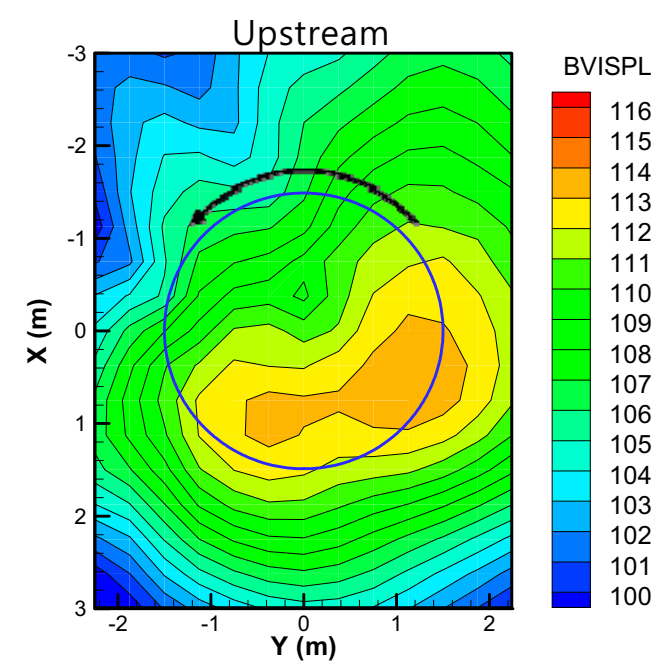

Fig. 25. Noise map (BVISPL, MN-3P, $A_{n}=6 \mathrm{~mm}, \varphi_{n}=30$ deg).

\subsection{Performance of Active Tab drive mechanism}

Two types of tests, namely a dynamic test and an endurance test, were conducted to examine and demonstrate the performance of the drive mechanism.

\subsubsection{Dynamic test}

Figure 26 shows the setup prepared for the dynamic test. 
The endurance test described later was also conducted using this setup.

A dynamic test was conducted to evaluate the operability of the Active Tab drive mechanism under the target conditions. For this objective, the Active Tab drive mechanism was operated with an input voltage of $50 \mathrm{~V} \pm 50 \mathrm{~V}$ at $2 / \mathrm{rev}$ $(43.3 \mathrm{~Hz})$ and $40 \mathrm{~V} \pm 40 \mathrm{~V}$ at $3 / \mathrm{rev}(65.0 \mathrm{~Hz})$ with a simulated lift of $20 \mathrm{~N}$ acting on the tab.

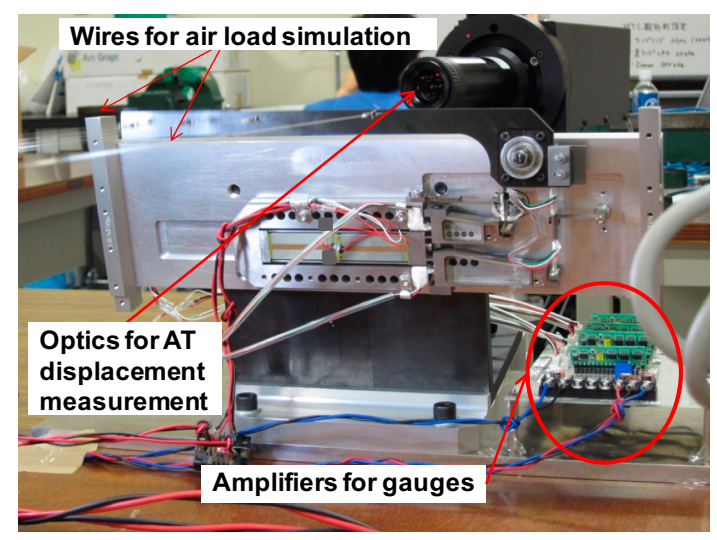

Fig. 26. Setup for dynamic and endurance tests.
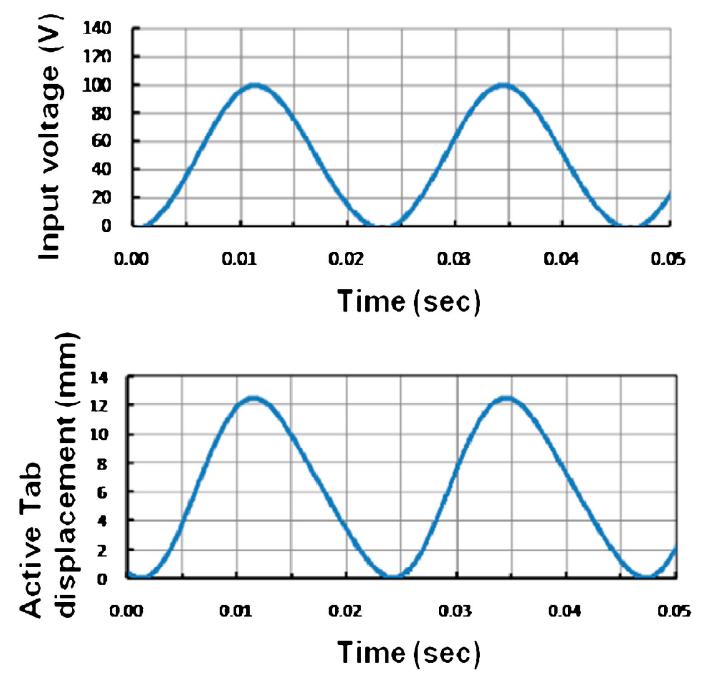

(a) Active Tab displacement and input voltage: time history 0 : Active Tab is completely retrieved. + : Active Tab is deployed.

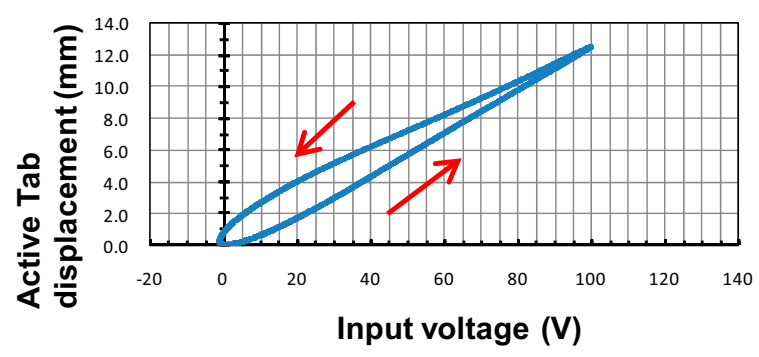

(b) Hysteresis of Active Tab displacement with respect to input voltage

Fig. 27. Dynamic characteristics of Active Tab drive mechanism. Input voltage $=50 \mathrm{~V} \pm 50 \mathrm{~V}$, Active Tab frequency $=2 / \mathrm{rev}(43.3 \mathrm{~Hz})$, with simulated lift of $20 \mathrm{~N}$ acting on tab.
Figure 27 shows the dynamic test results for $2 /$ rev cases and Fig. 28 shows the results for $3 /$ rev ones. These figures denote the dynamic behavior of the Active Tab drive mechanism measured by the Active Tab displacement generated with input voltage to the actuator measured simultaneously. As shown in Fig. 27(a) and Fig. 28(a), Active Tab drive mechanism displacement of $12 \mathrm{~mm}$ was obtained, which satisfies the requirement mentioned previously. Figure 27(b) and Fig. 28(b) show the hysteresis characteristics of Active Tab displacement with respect to input voltage. This hysteresis can be eliminated by managing feedback control during practical use of Active Tab in the blade.

\subsubsection{Endurance test}

The endurance test is to demonstrate the durability of the drive mechanism and examine the heat accumulating characteristics with respect to operation time.

For this test, the Active Tab drive mechanism was subjected to continuous operation with an input voltage of $50 \mathrm{~V} \pm 50 \mathrm{~V}$ at $43.3 \mathrm{~Hz}$ with a simulated lift of $20 \mathrm{~N}$ acting on the tab.

The duration target was set to a conservative 50 hours assuming other testing experience with the drive mechanism installed on a rotor system model and operated for a maxi-
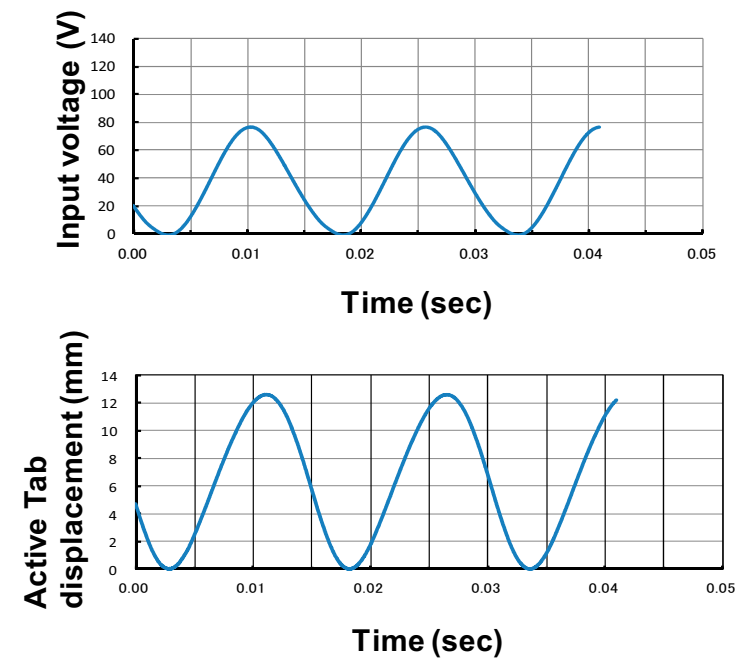

(a) Active Tab displacement and input voltage: time history 0 : Active Tab is completely retrieved. +: Active Tab is deployed.

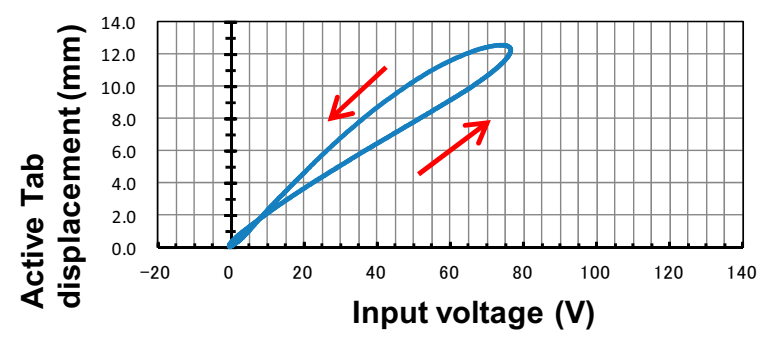

(b) Hysteresis of Active Tab displacement with respect to input voltage

Fig. 28. Dynamic characteristics of Active Tab drive mechanism. Input voltage $=40 \mathrm{~V} \pm 40 \mathrm{~V}$, Active Tab frequency $=3 / \mathrm{rev}(65.0 \mathrm{~Hz})$, with simulated lift of $20 \mathrm{~N}$ acting on tab. 


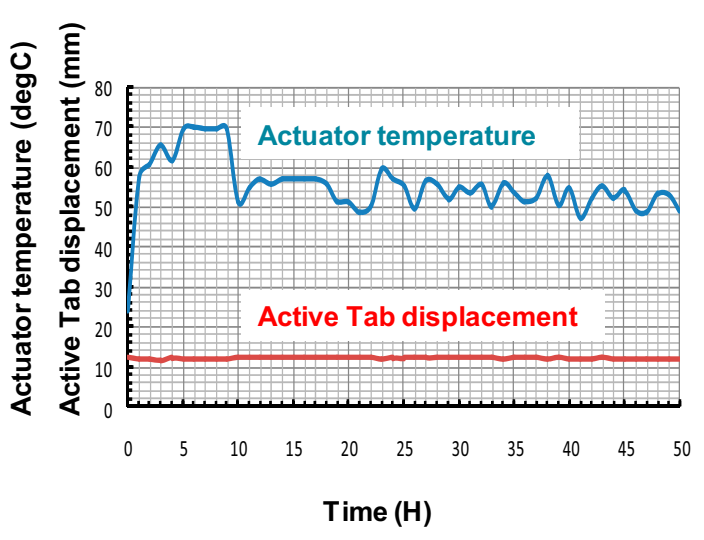

Fig. 29. Temporal variation of piezo actuator surface temperature and Active Tab displacement.

Input voltage $=50 \mathrm{~V} \pm 50 \mathrm{~V}$, Active Tab frequency $=2 / \mathrm{rev}(43.3 \mathrm{~Hz})$, with simulated lift of $20 \mathrm{~N}$ acting on tab.

mum of 20 hours with intermissions.

As shown in Fig. 29, the Active Tab drive mechanism worked successfully for 50 hours with insignificant temperature increase and deterioration of Active Tab displacement. Figure 29 shows a temporal variation of the temperature measured on the surface of the piezo actuator and Active Tab displacement when operating for 50 hours. The temperature increases sharply after activation, saturates to 50-60 degC and holds this value during operation.

This confirmed that the Active Tab drive mechanism is sufficiently durable for practical use when installed in helicopter blades, and causes no adverse characteristics of heat accumulation or mechanical trouble.

\section{Conclusions}

Summarizing the results, the following conclusions were reached in this study.

1. A CAMRAD II model for a rotor system with Active Tab was constructed using structural design and CFD analysis. The Active Tab drive mechanism was modeled as a lumped mass, and aerodynamic characteristics were implemented as 2-D airfoil tables with different tab chord lengths. BVI noise characteristics were analyzed using the airloads calculated by CAMRAD II. The analysis defined the requirements for Active Tab and its drive mechanism properties.

2. Variations of the BVI noise characteristics were investigated by applying HHC actuation of Active Tab. A BVISPL reduction of $3.3 \mathrm{~dB}$ was achieved using $3 / \mathrm{rev}$ actuation with $6 \mathrm{~mm}$ amplitude and a $30 \mathrm{deg}$ control phase angle.

3. An Active Tab drive mechanism that satisfies the requirements defined by analysis was developed.

4. The dynamic test demonstrated that the Active Tab drive mechanism developed achieves a $12 \mathrm{~mm}$ displacement at $2 / \mathrm{rev}$ and $3 / \mathrm{rev}$, and a simulated lift of $20 \mathrm{~N}$ acting on the tab, which satisfies the requirement. Although there is some hysteresis both in 2 /rev and 3 /rev operations, this hysteresis can be eliminated by managing the feedback control during practical use of Active Tab in the blade.

5. The Active Tab drive mechanism worked successfully for 50 hours with an insignificant rise in temperature and without mechanical trouble during the endurance test. This confirmed that the Active Tab drive mechanism developed has sufficient durability for practical use when installed in helicopter blades.

\section{References}

1) Splettstroesser, W. R., Lehmann, G., and v.d.Wall, B.: Initial Result of a Model Rotor Higher Harmonic Control (HHC) Wind Tunnel Experiment on BVI Impulsive Noise Reduction, 15th European Rotorcraft Forum, Amsterdam, The Netherlands, September 1989, Paper 01.

2) Splettstroesser, W. R., Schultz, K.-J., Kube, R., Brooks, T. F., Booth, E. R., Niesl, G., and Streby, O.: BVI Impulsive Noise Reduction by Higher Harmonic Pitch Control: Results of a Scaled Model Rotor Experiment in the DNW, 17th European Rotorcraft Forum, Berlin, Germany, September 1991, Paper 61.

3) Gmelin, B., Heller, H., Philippe, J. J., Mercker, E., and Preisser, J. S.: HHC Aeroacoustics Rotor Test at the DNW: The Joint German/ French/US HART Project, 20th European Rotorcraft Forum, Amsterdam, The Netherlands, October 1994, Paper 115.

4) Gmelin, B. L., Heller, H., Mercker, E., Philippe, J. J., Preisser, J. S., and Yu, Y. H.: The HART Programme: A Quadrilateral Cooperative Research Effort, 51st Annual Forum of the American Helicopter Society, Fort Worth, TX, May 1995, pp. 695-709.

5) Murashige, A., Kobiki, N., Tsuchihashi, A., Tsujiuchi, T., Inagaki, K., and Yamakawa, E.: Final Report of ATIC Model Rotor Test at DNW, 57th Annual Forum of American Helicopter Society, Washington, DC, May 9-11, 2001.

6) Jacklin, S., Blaas, A., Teves, D., and Kube, R.: Reduction of Helicopter BVI Noise, Vibration, and Power Consumption through Individual Blade Control, 51st Annual Forum of American Helicopter Society, Fort Worth, Texas, May 9-11, 1995.

7) Haber, A., Jacklin, S., and Simone, G.: Development, Manufacturing, and Component Testing of an Individual Blade Control System for a UH-60 Helicopter Rotor, American Helicopter Society Aerodynamics, Acoustics, and Test and Evaluation Specialists Meeting, San Francisco, CA, January 23-25, 2002.

8) Jacklin, S., Haber, A., Simone, G., Norman, T., Kitaplioglu, C., and Shinoda, P.: Full-Scale Wind Tunnel Test of an Individual Blade Control System for a UH-60 Helicopter, 58th Annual Forum of American Helicopter Society, Montréal, Canada, June 11-13, 2002.

9) Fürst, D., Keßler, C., Auspitzer, T., Müller, M., Hausberg, A., and Witte, H.: Closed Loop IBC-System and Flight Test Results on the CH-53G Helicopter, 60th Annual Forum of American Helicopter Society, Baltimore, MD, June 7-10, 2004.

10) Hasegawa, Y., Katayama, N., Kobiki, N., and Yamakawa, E.: Whirl Test Results of ATIC Full Scale Rotor System, 26th European Rotorcraft Forum, The Hague, The Netherlands, 2000.

11) Aoyama, T., Yang, C., and Saito, S.: Numerical Analysis of Active Flap for Noise Reduction Using Moving Overlapped Grid Method, 61st Annual Forum of the American Helicopter Society, Grapevine, TX, June 1-3, 2005.

12) Roth, D., Enenkl, B., and Dieterich, O.: Active Rotor Control by Flaps for Vibration Reduction-Full Scale Demonstrator and First Flight Test Results-, 32nd European Rotorcraft Forum, Maastricht, The Netherlands, 2006.

13) Straub, F. and Anand, V.: Aeromechanics of the SMART Active Flap Rotor, 63rd Annual Forum of American Helicopter Society, Virginia Beach, VA, May 1-3, 2007.

14) Kobiki, N. and Saito, S.: Performance Evaluation of Full Scale On-board Active Flap System in Transonic Wind Tunnel, 64th Annual Forum of American Helicopter Society, Montreal, Canada, April 29May 1, 2008.

15) Lorber, P., O’Neil, J., Isabella, B., Andrews, J., Brigley, M., Wong, J., and LeMasurier, P.: Whirl and Wind Tunnel Testing of the Sikorsky Active Flap Demonstration Rotor, 67th Annual Forum of American 
Helicopter Society, Virginia Beach, VA, May 3-5, 2011.

16) Bernhard, A. and Wong, J.: Sikorsky Active Rotor Control Evaluation of NASA/Army/MIT Active Twist Rotor, 59th Annual Forum of American Helicopter Society, Phoenix, Arizona, May 6-8, 2003.

17) Weems, D., Anderson, D., Mathew, M., and Bussom, R.: A LargeScale Active-Twist Rotor, 60th Annual Forum of American Helicopter Society, Baltimore, MD, June 7-10, 2004.

18) Wierach, P., Riemenschneider, J., Optiz, S., and Hoffmann, F.: Experimental Investigation of an Active Twist Model Rotor Blade under Centrifugal Loads, 33rd European Rotorcraft Forum, Kazan, Russia, September 11-13, 2007.

19) International Standards and Recommended Practices, ENVIRONMENTAL PROTECTION, Annex16 to the Convention on International Civil Aviation, Volume I Aircraft Noise, Chapter 8 and 11.

20) Kobiki, N., Kondo, N., Saito, S., Akasaka, T., and Tanabe, Y.: An Experimental Study of On-blade Active Tab for Helicopter Noise Reduction, 30th ERF, France, September 2004.

21) Kobiki, N., Saito, S., Akasaka, T., Tanabe, Y., and Fuse, H.: An Experimental Study for Aerodynamic and Acoustic Effects of On-blade Active Tab, 31st ERF, Italy, September 2005.

22) Aoyama, T., Yang, C., and Saito, S.: Numerical Analysis of BVI Noise Reduction by Active Tab, 60th American Helicopter Society Annual Forum, Baltimore, MD, June 7-10, 2004.

23) Kobiki, N.: Design and Performance Evaluation for Finalized Active Tab Drive Mechanism Installed in Mach Scaled Model Blade, 39th ERF, Moscow, Russia, September 2013.

24) Leishman, J. G.: Principles of Helicopter Aerodynamics, 2nd Ed., Cambridge University Press, Cambridge, UK, 2016.

25) Kim, D.-H. and Kim, S.-H.: Design of a Dynamically Scaled Rotor
System and Verification of the Blade Properties, 37th ERF, Gallarate, Italy, September 2011

26) Johnson, W.: Rotorcraft Aerodynamics Models for a Comprehensive Analysis, 54th AHS Annual Forum, Washington, DC, May 20-22, 1998.

27) Norman, T., Shinoda, P., Fuerst, D., Arnold, U., Lorber, P., and O'Neill, J.: Full-scale Wind Tunnel Test of a UH-60 Individual Blade Control System for Performance Improvement and Vibration, Loads, and Noise Control, AHS 65th Annual Forum, Grapevine, TX, May 27-29, 2009.

28) Brentner, K. S. and Farassat, F.: Modeling Aerodynamically Generated Sound of Helicopter Rotors, Progress in Aerospace Sciences, Vol. 39, Elsevier Science Ltd., Amsterdam, The Netherlands, 2003, pp. 83120.

29) Schmitz, F. H.: Rotor Noise, Aeroacoustics of Flight Vehicles: Theory and Practice, Volume 1: Noise Sources, Hubbard, H. H. (ed.), NASA RP-1258, Vol. 1, WRDC TR-90-3052, 1991, pp. 102-106.

30) Kobiki, N. and Saito, S.: A Conceptual Design of Active Tab for Mach Scaled Model Blade Installation, 36th ERF, Paris, France, September 2010.

31) Kobiki, N.: Performance Evaluation for Active Tab Installed in Mach Scaled Model Blade, 37th ERF, Gallarate, Italy, September 2011.

32) Kobiki, N.: Design and Performance Evaluation for Enhanced Active Tab Drive Mechanism Installed in Mach Scaled Model Blade, 38th ERF, Amsterdam, The Netherlands, September 2012.

Shigeru Saito Associate Editor 